\title{
Sub-Chronic Toxicity Study of Fixed Dose Combination of Ofloxacin- Ornidazole in Mus Musculus Mice
}

\author{
Manu Chaudhary, Anupama Tamta and Rajesh Sehgal*
}

Intellectual Scientific Division, Venus Medicine Research Centre, Venus Remedies limited, Haryana, India

\begin{abstract}
The present study investigated safety/toxicity profile of fixed dose combination of Ofloxacin-Ornidazole injection in Mus musculus mice at three dose levels, ranging from asymptomatic to high dose. To enhance the antimicrobial spectrum of the quinolones against anaerobic organisms and gram positive bacteria, fixed dose combination of Ofloxacin and Ornidazole injection was introduced. It has been found highly effective as well as synergistic and has the potential of usage for empirical therapy because of extended spectrum. A 30 days repeat dose subchronic toxicity study was conducted on mice (male and female). Various physiological, hematological and biochemical parameters were studied. There were no signs of toxicity observed at any dose level used in this study. No mortality was seen in any of the treatment groups. Hematological as well as physiological parameters were unaltered at three dose levels in Ofloxacin-Ornidazole treatment groups. Results suggest that the fixed dose combination of Ofloxacin-Ornidazole injection is non toxic even at maximum dose level.
\end{abstract}

Key Words: Ofloxacin /Ornidazole, Fluoroquinolone, Sub-chronic toxicity, FDC.

\section{INTRODUCTION}

The development of the fluoroquinolones has resulted in antimicrobial agents with enhanced gram-negative activity, including moderate activity against Pseudomonas aeruginosa $[1,2]$. However, despite the broad antibacterial spectrum of quinolones, most anaerobic pathogens and several gram-positive strains such as Staphylococci and Streptococci are only moderately susceptible $[2,3]$. Thus, in some clinical situations, a combination with other antibacterial agents is needed to broaden the antibacterial spectrum. Examples are miscellaneous infections with aerobic and anaerobic bacteria (such as aspiration pneumonia or intra- abdominal infections) for which initial therapy has to be empiric, or the empiric therapy of febrile neutropenic patients [4]. Ornidazole have an antibacterial spectrum that includes most anaerobes $[4,5]$ and single-dose ornidazole is an important alternative agent for the treatment of many conditions than other nitroimidazoles $[4,6]$. Thus this combination was developed to cover all treatment related aspects and to widen the spectrum of activity of these two agents.

The other aspect of innovating fixed dose combinations (FDCs) is emergence of high resistance of Pseudomonas aeruginosa against various commonly used antibiotics, especially in fluoroquinolones, which is an alarming situation. The control of drug resistant Pseudomonas aeruginosa required rational prescribing and proper use of antibiotics [1,7].

Ofloxacin is a synthetic fluoroquinolone that inhibits the supercoiling activity of bacterial DNA gyrase, halting DNA

*Address correspondence to this author at the Intellectual Scientific Division, Venus Medicine Research Centre, Venus Remedies limited, Hill Top, Industrial Estate, Jharmajiri EPIP, Phase I Extension, Baddi (H.P), 173205, India; Tel: +91-1795-302100; Fax: +91-1795-302023;

E-mail: vmrc@venusremedies.com replication [6, 8] whereas Ornidazole is a nitroimidazole anti-infective medication that is mainly used in the treatment of infections caused by susceptible organisms, particularly anaerobic bacteria and protozoa [9]. The nitro group of Ornidazole is chemically reduced by ferredoxin (or a ferredoxin-linked metabolic process) and the products are responsible for disrupting the DNA helical structure, thus inhibiting nucleic acid synthesis. Anaerobic bacteria and sensitive protozoal organisms take Ornidazole selectively because of the ability of these organisms to reduce Ornidazole to its active form intracellularly [5].

The parenteral formulation of ofloxacin has been developed with favorable pharmacokinetic properties [10], including high serum concentrations and a long terminal half-life, resulting in a higher area under the concentration-time curve (AUC) than other fluroquinolones [11, 12]. Ornidazole is already a parentral formulation. Apart from this there are no available reports of kinetic interaction reported between Ofloxacin and Ornidazole [5, 13].

The major hurdle in fabricating fixed dose combination is their toxicity profile which may also worsened in a synergistic pattern. Several reports are available on toxicity study of individual agents [14] but safety profile of combination product has not been established yet. We have first time conducted the toxicity study on FDC Ofloxacin-Ornidazole. The purpose of current study was to evaluate safety profile/ toxicity potential of fixed dose combination OfloxacinOrnidazole injection in mice by sub chronic dosing.

\section{MATERIAL AND METHOD}

\section{Animals}

Healthy Mus musculus mice (male and female mice, 15$25 \mathrm{~g}$ weight) were divided into four groups (three treatment 
groups and one control group). Each group consists of 6 male and 6 female animals. Animals were provided with standard diet (pellets) supplied by Amrut feed India and water was given ad libitum. They were housed in polyurethane cages (six in each) at controlled room temperature of 29 $\pm 2{ }^{\circ} \mathrm{C}$ and a relative humidity of $50.5 \%$, and a constant lightdark schedule (12 hours light and 12 hour dark cycle).

\section{Experimental Design and Drug Treatment}

Ofloxacin-Ornidazole was given as intravenous injection at three dose levels i.e. $56 \mathrm{mg} / \mathrm{kg}, 175 \mathrm{mg} / \mathrm{kg}$ and $560 \mathrm{mg} / \mathrm{kg}$ correspond to low dose, intermediate dose and high dose respectively ( $1: 2.5$ ratio of Ofloxacin : Ornidazole) for thirty days. Normal saline was administered to the animals of control group as sham treatment. Treatment was done once daily for continuous 30 days.

Physical parameters (body weights, food and water intake) and local injury were studied throughout the treatment. Mortality if any, in all the groups, during the course of treatment was also recorded. Autopsy was done if animal died during course of treatment. At the end of treatment haematological, biochemical (liver function tests \& renal function tests) and histological parameters were studied. The organs were quickly blotted, weighed on digital balance and processed for histological studies. The organ body weight ratio of each organ was calculated and tissues were processed for H\& E staining.

\section{Hematological}

Blood was collected by cardiac puncture. Blood samples were analyzed for routine hematological parameters. Blood cell count was done with blood smears. Hemogram was performed on ACT diff-2 Hematolgy Analyzer (Beckman Coulter India Ltd., Mumbai, India).

\section{Biochemical Parameters}

Biochemical parameters were performed in serum sample. Gluatmic oxaloacetic transaminase (GOT), gluatmic pyruvic transaminase activities (GPT), alkaline phosphatase (ALP) activities and triglycerides (TG), bilirubin, cholesterol, blood urea nitrogen (BUN), protein, creatinine and glucose levels were estimated. Sodium, potassium and chloride levels were estimated for evaluating electrolyte balance in serum. All parameters were studied by Merck semi auto analyzer by using Merck analytical kits.

\section{Histological Examination}

At the end of treatment animals were sacrificed and various organs like liver, kidney, lungs and gonads were collected for histological examinations. All the organs were immediately fixed in $10 \%$ buffered formalin. H\&E staining was done and slides were studied for histological changes.

\section{Statistical Analysis}

Results are shown as Mean \pm SD. Significance of difference between groups was evaluated by using ANOVA. If ANOVA shows significant differences, post hoc analysis was performed with Tukey test. $\mathrm{P}<0.05$ was considered as statistically significant.
The study protocol for study was approved by Institutional animal ethics committee of Institute for Toxicological Studies, Pune, India. Drug was procured from Venus Remedies Limited.

\section{RESULTS}

\section{Physical Parameters}

No physical changes were observed throughout the dosing period. There was no significant change in the mean body weight of the animals in FDC treated groups as compared to vehicle treated control group at the end of treatment.

\section{Hematology}

No significant changes were observed in red blood cell (RBC), ESR, hemoglobin (Hb), total leukocyte counts (TLC) and platelet counts in all the treated groups as compared to respective control groups (Tables 1 and 2). PCV decreased in high dose treated groups which was insignificant (Tables $\mathbf{1}$ and 2).

\section{Biochemical Parameters}

In male and female mice groups, no significant changes were seen in serum creatinine, bilirubin, total protein, sodium, potassium and plasma chloride levels in all the groups as compared to control group (Tables $\mathbf{3}$ and $\mathbf{4}$ ). Slight increase was observed at high dose level in serum glucose, BUN, GPT, GOT activities, alkaline phosphatase activities in all the treated groups as compared to respective control group, however change was statistically insignificant (Tables 3 and 4).

\section{Histological Examination}

There were no significant treatment related histopathological changes observed in organs of all the treated groups as compared to control.

\section{DISCUSSION}

This study demonstrates the safety profile of potential FDC Ofloxacin-Ornidazole in mice. Despite the broad antibacterial spectrum of Ofloxacin, most anaerobic and several gram- positive bacteria are only moderately susceptible. To cover this lacuna in spectrum of activity, a combination with onidazole was hypothesized. A primary effect of quinolones is inhibition of bacterial DNA synthesis in the presence of competent RNA and protein synthesis $[3,15]$. Thus, interactions and antagonism with other potent protein synthesis inhibitors cannot be ruled out.

Combinations of quinolones with other antimicrobial agents investigated in in-vitro and in vivo studies rarely showed antagonistic effects [16]. Against anaerobic bacteria the results of combination drug were very encouraging. Combination of quinolones with ornidazole, and other drugs investigated, showed synergistic activity with Ofloxacin [13, 17]. The available reports showed synergy for the combinations of ciprofloxacin with metronidazole (a similar combination) against members of the family Enterobacteriaceae, peptostreptococci, and clostridia [18]. Other studies have also reported similar synergism with quinolones and nitro- 
Table 1. Effect of Thirty Days Treatment with Three Doses of FDC Ofloxacin-Ornidazole on Hemogram in Male Mice

\begin{tabular}{|c|c|c|c|c|}
\hline & Control & $56 \mathrm{mg} / \mathrm{kg}$ & $175 \mathrm{mg} / \mathrm{kg}$ & $560 \mathrm{mg} / \mathrm{kg}$ \\
\hline $\mathrm{Hb}(\mathrm{g} \%)$ & $12.50 \pm 1.12$ & $12.45 \pm 1.01$ & $12.45 \pm 1.03$ & $12.30 \pm 1.15$ \\
\hline $\mathrm{RBC}(\mathrm{x} 106 / \mathrm{cmm})$ & $6.32 \pm 0.52$ & $6.30 \pm 0.65$ & $6.28 \pm 0.89$ & $6.25 \pm 0.45$ \\
\hline Polycytes (x106/cmm) & $65.02 \pm 5.21$ & $66.25 \pm 6.32$ & $67.21 \pm 7.21$ & $70.02 \pm 5.21$ \\
\hline Lymphocyte (x106/cmm) & $35.66 \pm 5.21$ & $35.65 \pm 6.33$ & $36.52 \pm 4.21$ & $37.24 \pm 8.21$ \\
\hline Eosinophil(x106/cmm) & $1.25 \pm 0.23$ & $1.50 \pm 0.52$ & $1.65 \pm 0.65$ & $1.70 \pm 1.00$ \\
\hline Monocytes (x106/cmm) & $2.00 \pm 0.50$ & $3.00 \pm 0.80$ & $4.00 \pm 0.20$ & $2.00 \pm 0.40$ \\
\hline Platelets (x106/cmm) & $353625.0 \pm 1025.3$ & $359584.0 \pm 25365.0$ & $373654.0 \pm 2514.3$ & $383525.0 \pm 552132.01$ \\
\hline
\end{tabular}

Results are expressed as Mean \pm S.D. $n=5-6$.

Table 2. Effect of Thirty Days Treatment with Three Doses of FDC Ofloxacin-Ornidazole on Hemogram in Female Mice

\begin{tabular}{|c|c|c|c|c|}
\hline & Control & $56 \mathrm{mg} / \mathrm{kg}$ & $175 \mathrm{mg} / \mathrm{kg}$ & $560 \mathrm{mg} / \mathrm{kg}$ \\
\hline $\mathrm{Hb}(\mathrm{g} \%)$ & $12.40 \pm 1.45$ & $12.35 \pm 1.70$ & $12.30 \pm 1.54$ & $12.20 \pm 1.35$ \\
\hline $\mathrm{RBC}(\mathrm{x} 106 / \mathrm{cmm})$ & $6.45 \pm 1.00$ & $6.40 \pm 0.98$ & $6.31 \pm 0.85$ & $6.25 \pm 1.20$ \\
\hline Polycytes (x106/cmm) & $69.25 \pm 2.31$ & $70.21 \pm 6.32$ & $73.21 \pm 4.01$ & $74.00 \pm 5.21$ \\
\hline Lymphocyte (x106/cmm) & $35.45 \pm 2.52$ & $35.61 \pm 4.12$ & $35.95 \pm 5.33$ & $36.21 \pm 8.21$ \\
\hline Eosinophil(x106/cmm) & $1.50 \pm 0.21$ & $1.65 \pm 0.01$ & $1.70 \pm 0.45$ & $1.75 \pm 0.65$ \\
\hline Monocytes (x106/cmm) & $2.50 \pm 0.45$ & $3.00 \pm 0.00$ & $4.50 \pm 0.80$ & $3.50 \pm 0.50$ \\
\hline Platelets (x106/cmm) & $382595.0 \pm 12325.0$ & $396541.0 \pm 25362.0$ & $401001.0 \pm 236541.2$ & $410000.0 \pm 2356.2$ \\
\hline
\end{tabular}

Results are expressed as Mean \pm S.D. $n=5-6$.

imidazoles [13]. The major issue which required to be addressed was evaluation of toxicity profile of FDC.

Our study was designed to investigate possible toxic outcomes of this promising therapeutic choice. There was no signs of local injury and inflammatory response at site of injection in the treated groups. No physical changes were observed during the study period of 30 days in all the treatment groups. Increase in body weights and growth of treated animals of either sex were of similar pattern as in control groups. Published evidences also suggested no treatmentrelated changes in physical and organs in any species $[19,20]$.
Blood was evaluated for hematological toxicity of FDC. Hemogram was estimated and results had shown no deleterious effect on blood cell count, haemoglobin and other related parameters in treated animals (Table 1 and 2). There was no significant changes in plasma alkaline phosphatase, GOT and GPT activities in Ofloxacin-Ornidazole treated groups of either sex as compared to the respective control group (Table 3 and 4). This confirms the safety profile of Ofloxacin/ Ornidazole injection in hepatic related aspects. Available reports proved efficacy of Ofloxacin as well as 5-nitroimidazoles (Ornidazole) against a range of microorganisms 
Table 3. Effect of Thirty Days Treatment with Three Doses of FDC Ofloxacin-Ornidazole on Biochemical Parameters in Male Mice

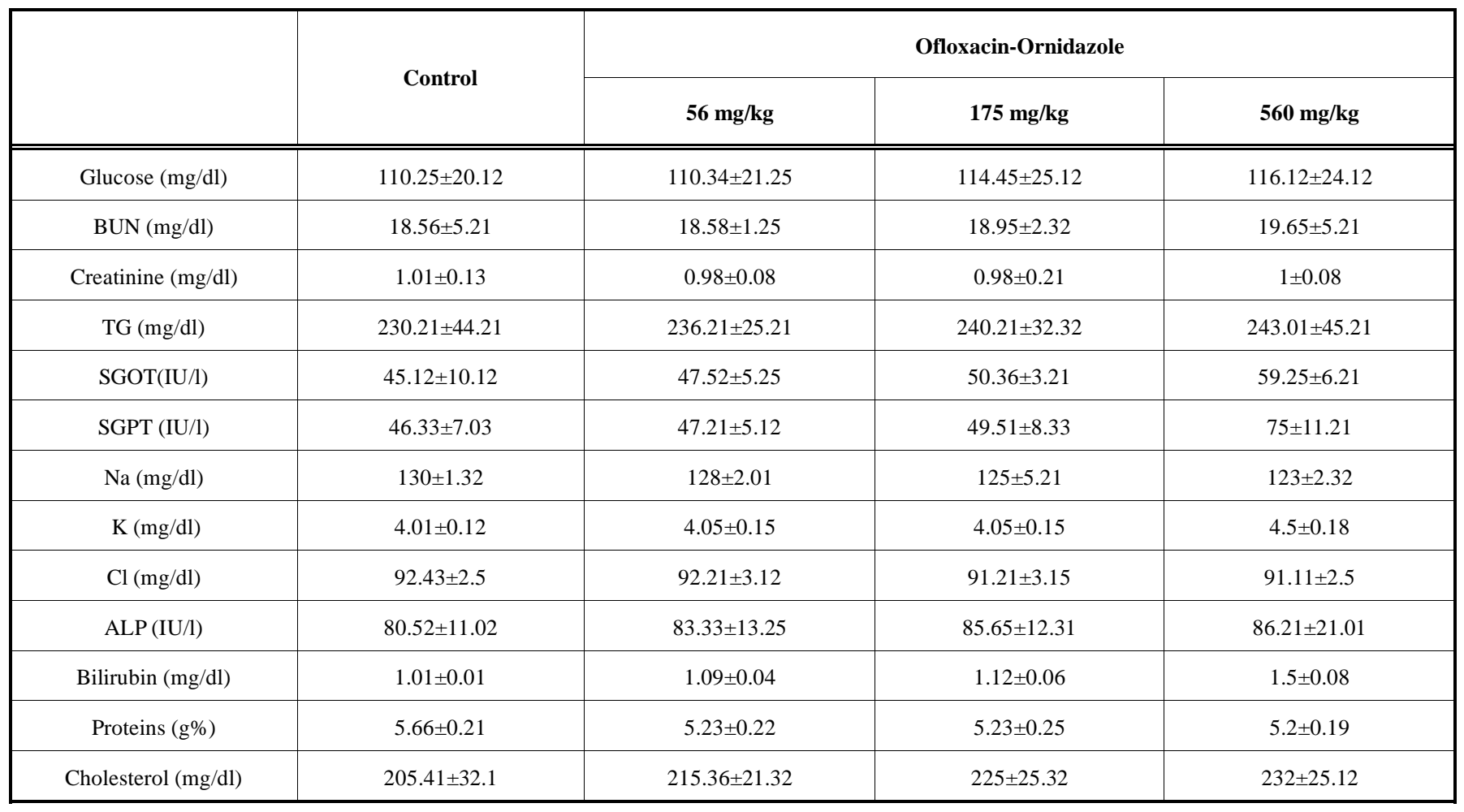

Results are expressed as Mean \pm S.D. $n=5-6$.

Table 4. Effect of Thirty Days Treatment with Three Doses of FDC Ofloxacin-Ornidazole on Biochemical Parameters in Female Mice

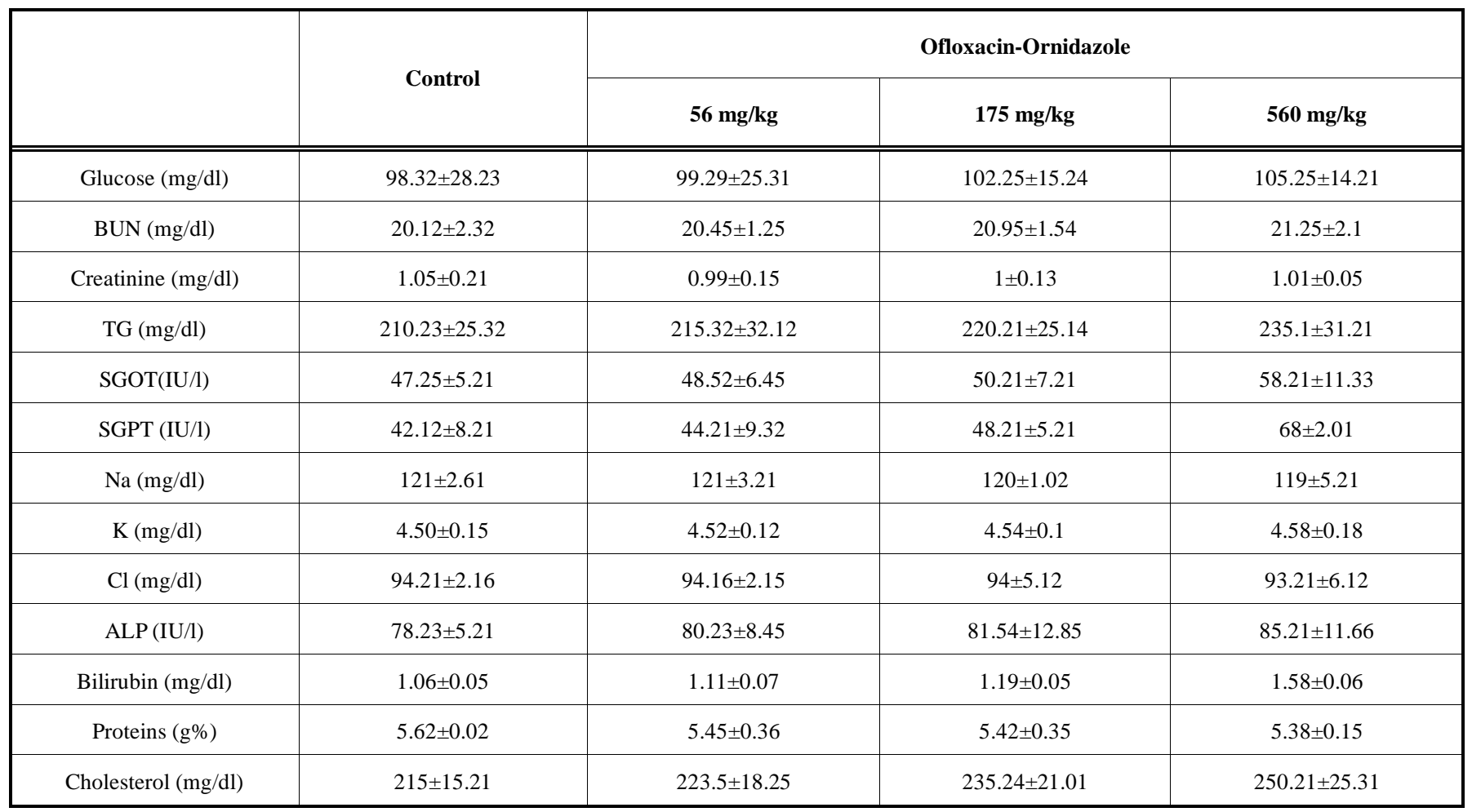

Results are expressed as Mean \pm S.D. $n=5-6$ 
and also found it safe in the short-term as well as the longterm usage [21-23].

Ofloxacin-ornidazole eliminated through renal excretion, thus it is mandatory to estimate effects of FDC on kidney functions [5, 6, 24]. Biochemical parameters related to kidney function were evaluated and no significant differences were observed in BUN, creatinine, glucose and proteins with respect to control (Table 3 and 4). Previous reports also suggested no dose-limiting toxicity observed in the trial of ornidazole and ofloxacin. It was found safe, well tolerated, and associated with improvement in the inflammatory symptoms [20, 23, 24].

There were no signs of toxicity were seen in any of organ in histopathological analysis. No mortality was occurred throughout the study. Thus histopathological studies provides supports to the safety data of other physiological, biochemical and heamatological parameters of OfloxacinOrnidazole injection [8, 21].

In summary, our data suggest that combination of Ofloxacin-Ornidazole is safe even at higher doses than intended to be use for human treatment as it indicates no clinically relevant alterations of any of physiological and biochemical parameters. A beneficial effect of combination against grampositive and anaerobic pathogens could be demonstrated/established with bacterial susceptibility tests .

It can be concluded that in preclinical settings (subchronic dosing), a parenteral therapy consisting of modern quinolones together with imidazole derivative ornidazole as fixed dose combination appears to be active and offers no obvious toxicity at any dose level.

\section{ACKNOWLEDGEMENT}

Authors are thankful to Financial department of R \& D Centre, Venus Remedies Limited, India for the financial support.

\section{ABBREVIATIONS}

$$
\begin{aligned}
& \text { ESR }=\text { Erythrocyte sedimentation rate } \\
& \text { PVC }=\text { Packed cell volume } \\
& \text { TG }=\text { Triglycerides } \\
& \text { GOT }=\text { Gluatmic oxaloacetic transaminase } \\
& \text { GPT }=\text { Gluatmic pyruvic transaminase activities } \\
& \text { BUN }=\text { Blood Urea Nitrogen } \\
& \text { FDC }=\text { Fixed Dose Combination } \\
& \text { Hb }=\text { Hemoglobin } \\
& \text { ALP }=\text { Alkaline Phosphatase }
\end{aligned}
$$

\section{REFERENCES}

[1] Khan JA, Iqbal Z, Rahman SU, Farzana K, Khan A. Prevalence and resistance pattern of Pseudomonas aeruginosa against various antibiotics. Pak J Pharm Sci 2008; 21(3): 311-5.

[2] Messadi AA, Lamia T, Kamel B, Salima O, Monia M, Saida BR. Association between antibiotic use and changes in susceptibility patterns of Pseudomonas aeruginosa in an intensive care burn unit: A 5-year study 2000-2004. Burns 2008; 341(8): 1098-102.

[3] Hamilton-Miller JM, Shah S. Activities of ciprofloxacin, levofloxacin, ofloxacin and sparfloxacin against speciated coagulasenegative staphylococci sensitive and resistant to fluoroquinolones. Int J Antimicrob Agents 1997; 9(2): 127-30.

[4] Kurt O, Girginkardesler N, Balcioglu IC, Ozbilgin A, Ok UZ. A comparison of metronidazole and single-dose ornidazole for the treatment of dientamoebiasis. Clin Microbiol Infect 2008; 14(6): 601-4.

[5] Kumar YS, Ramesh S, Rao YM, Paradkar AR. Effect of rifampicin pretreatment on the transport across rat intestine and oral pharmacokinetics of ornidazole in healthy human volunteers. Drug Metab Drug Interact 2007; 22(2-3): 151-63.

[6] Saraçoglu F, Gol K, Sahin I, Türkkani B, Atalay C, Oztopçu C. Treatment of bacterial vaginosis with oral or vaginal ornidazole, secnidazole and metronidazole. Int J Gynaecol Obstet 1998; 62(1): 59-61.

[7] Aggarwal R, Chaudhary U, Bala K. Detection of extendedspectrum beta-lactamase in Pseudomonas aeruginosa. Indian J Pathol Microbiol 2008; 51(2): 222-4.

[8] Cornaglia G, Concan R, Arrigucci S, Novelli A. Antibacterial activity and pharmacological features of fluoroquinolones and considerations on their use in a nosocomial setting. Infez Med 2007; 15 (4): 211-36.

[9] Ogrendik M. Levofloxacin treatment in patients with rheumatoid arthritis receiving methotrexate. South Med J 2007; 100(2): 135-9.

[10] Gascón AR, Campo E, Hernández RM, Calvo B, Errasti J, Pedraz JL. Pharmacokinetics and tissue distribution of intravenous ofloxacin for antibiotic prophylaxis in biliary surgery. Clin Drug Investig 1998; 15(6): 491-6.

[11] Kelly A, Sprandel L, Christopher A, et al. Pharmacokinetics and pharmacodynamics of intravenous levofloxacin at 750 milligrams and various doses of metronidazole in healthy adult subjects. Antimicrob Agents Chemother 2004; 48(12): 4597-605.

[12] Ptitsina SN, Bobrov VI, Borisov MM. Chemotherapy activity and pharmacokinetics of the fluoroquinolones generics Ofloxacin$\mathrm{PhPO}$ and Pefloxacin-genova. Antibiot Khimioter 2007; 52(6): 136.

[13] Boeckh M, Lode H, Deppermann KM, et al. Pharmacokinetics and serum bactericidal activities of quinolones in combination with clindamycin, metronidazole, and ornidazole. Antimicrob Agents Chemother 1990; 34(12): 2407-14.

[14] Jong-Choon K, Dong-Ho S, Sung-Ho K, et al. Developmental toxicity evaluation of the new fluoroquinolone antibacterial DW116 in rats. Teratog Carcinog Mutagen Suppl 2003; 1: 123-36.

[15] Drugeon HB, Juvin ME, Bryskier AJ. Relative potential for selection of fluoroquinolone-resistant Streptococcus pneumoniae strains by levofloxacin: comparison with ciprofloxacin, sparfloxacin and ofloxacin. Antimicrob Chemother 1999; 43(Suppl C): 55-9.

[16] Hemanth Kumar AK, Gurumurthy P. Ofloxacin pharmacokinetics in saliva. Indian J Pharmacol 2004; 36(2): 80-3.

[17] Paladino JA, Gilliland-Johnson KK, Adelman MH, Cohn SM. Pharmacoeconomics of ciprofloxacin plus metronidazole vs. piperacillin-tazobactam for complicated intra-abdominal infections. Surg Infect (Larchmt) 2008; 9(3): 325-33.

[18] Werk R, Schneider L. Ciprofloxacin in combination with metronidazole. Infection 1988; 16: 257-60.

[19] Ogrendik M. Treatment of rheumatoid arthritis with ornidazole: a randomized, double-blind, placebo-controlled study. Rheumatol Int 2006; 26(12): 1132-7.

[20] Rutgeerts P, Van Assche G, Vermeire S, et al. Ornidazole for prophylaxis of postoperative Crohn's disease recurrence: a randomized, double-blind, placebo-controlled trial. Gastroenterology 2005; 128(4): 856-61.

[21] Yamano T, Morizono T, Shiraishi K, Miyagi M, Imamura A, Kato T. Safety of ofloxacin (OFLX) and fosfomycin sodium (FOM) ear drops. Int J Pediatr Otorhinolaryngol 2007; 71(6): 979-83.

[22] Roe FJ. Safety of nitroimidazoles. Scand J Infect Dis Suppl 1985; 46: 72-81.

[23] Kato M, Furuhama K, Yoshida M, Akahane K, Takayama S. Acute oral toxicity of the new quinolone antibacterial agent levofloxacin in mice, rats and monkeys. Arzneimittelforschung 1992; 43(3A): 365-6. 
[24] Inage F, Kato M, Yoshida M, Akahane K, Takayama S. Lack of nephrotoxic effects of the new quinolone antibacterial agent levofloxacin in rabbits. Arzneimittelforschung 1992; 43(3A): 3957.

(C) Chaudhary et al.; Licensee Bentham Open.

This is an open access article licensed under the terms of the Creative Commons Attribution Non-Commercial License (http://creativecommons.org/licenses/ by-nc/3.0/) which permits unrestricted, non-commercial use, distribution and reproduction in any medium, provided the work is properly cited. 